\title{
A REVERSIBILIDADE ONTOLÓGICA NO CONCEITO DE IMANÊNCIA
}

\author{
Symon Sales Souto ${ }^{1}$ \\ Universidade Federal de Santa Maria (UFSM) \\ https://orcid.org/0000-0002-6843-2737 \\ E-mail: symonsalesouto@gmail.com
}

\section{RESUMO:}

O estudo que se segue, tratar-se-á, a prima facie, de uma tentativa de justificar a necessidade de Michel Henry em radicalizar o método fenomenológico a fim de conceber a dualidade visível-invisível na Imanência absoluta de um sujeito patético sem, contudo, afastar-se do campo fenomenológico. No entanto, nos será preciso entender que suas considerações se tratam de um projeto onto-fenomenológico pois, segundo o autor, é apenas submetendo toda a ontologia à fenomenologia que o desvelar do Ser é suscetível de dar-se em sua plenitude. Nesta medida, espera-se com esse artigo apresentar-lhes os argumentos principais da Onto-Fenomenologia Material de Michel Henry arguindo, por sua vez, que seu projeto filosófico não se trata de metafísica e, tampouco, de mística. Em sentido oposto, mostraremos em que medida a Filosofia Material de Michel Henry deve ser considerada ontologia e seu método fenomenológico. Para tal utilizaremos como base, em especial, L'essence de laManifestation e Phenomenologie Materielle.

PALAVRAS-CHAVES: Método fenomenológico; Imanência; Ser; Absoluto; Invisível.

\section{THE ONTOLOGICAL REVERSIBILITY IN THE CONCEPT OF IMANENCE}

\begin{abstract}
:
The following study will deal with prima facie, of an attempt to justify Michel Henry's need to radicalize the phenomenological method in order to conceive the visible-invisible duality in the absolute immanence of a pathetic subject without, however, departing from the phenomenological field. However, we will need to understand that their considerations are an Onto-Phenomenological project because, according to him, It is only by subjecting all ontology to phenomenology that the unveiling of Being is likely to take place in its fullness. In this sense, it is hoped with this article to present to them the main arguments of Michel Henry's material onto-phenomenology arguing, in turn, that his philosophical project is not about metaphysics, nor mystique. Conversely, we will show to what extent Michel Henry's Material Philosophy should be considered ontology and its phenomenological method. For this we will use as a base, in particular, L'essence de la Manifestation and Phenomenologie Materielle.
\end{abstract}

KEYSWORDS: Phenomenological method; Immanence; Being; Absolute; Invisible.

${ }^{1}$ Doutorando em Filosofia na Universidade Federal de Santa Maria (UFSM), Santa Maria - RS, Brasil.

SOUTO, Symon Sales. A reversibilidade ontológica no conceito de imanência. Griot : Revista de Filosofia, Amargosa - BA, v.20, n.2, p.61-74, junho, 2020. 


\section{A recepção da fenomenologia pela filosofia contemporânea francesa: Emmanuel Levinás e Michel Henry, leitores de Edmund Husserl}

Segundo Husserl devemos ater-nos aos fenômenos sem pressupostos ou prejuízos, tomando-o tal como se dá, dentro dos limites em que se dá. Deste modo, sua doação não estaria "fora do conhecimento, fora da consciência e, ao mesmo tempo, estaria dada no sentido de absoluta autopresentação de algo puramente intuído" (HUSSERL, 1986, p. 69). Comentando a respeito, Sokolowski pontua que, com Husserl, "significado, verdade e raciocínio lógico, não são apenas características de nossa constituição psicológica ou biológica, mas entra em um novo domínio que está além deste, a saber, o domínio das essências" (2005, p. 126). Nesse sentido, entende-se que a tarefa da Fenomenologia consiste em "dilucidar os nexos entre verdadeiro ser e conhecer e, deste modo, investigar em geral as correlações entre ato, significação e objeto" (HUSSERL, 1990, p.13). ${ }^{2}$ Eis, pois, a "ciência da essência do conhecimento ou doutrina universal das essências" (HUSSERL, 1990, p.22).

A fenomenologia contemporânea francesa, em especial, as considerações de Emmanuel Levinás e Michel Henry partem de uma análise crítica à fenomenologia de Edmund Husserl que, segundo os autores, toca o ser na sua originalidade, no entanto, ao colocar a intencionalidade no cerne de toda a fenomenologia deixara escapar o essencial da 'coisa mesma', haja vista que, "essa doação do 'referir-se a' da cogitatio original pela vista pura na qual o fenomenólogo vê dito 'referir-se $a^{\prime}$, é uma ilusão" (HENRY, 2009, p.154, grifos do autor). Isto é, aos olhos de Michel Henry, o 'referir-se à' da cogitatio real pela vista pura oculta a autodoação desse dito 'referir-se $\grave{a}$ ' e, ocultandoa, "renuncia sua pretensão mais última, a pretensão ontológica de dar o ser" (2009, p.120). Nesta medida, "a elucidação do que está implicado no dado que aparece [ledonné] não pode prosseguir-se mais que se o que é dado [cedonné] sacrifica sua presença ao desenvolvimento ulterior do processo fenomenológico" (HENRY, 1963, p. 63, grifos do autor).

Levinás (1959), observa que ao centrar-se, exclusivamente, no psiquismo da correlação, Husserl coloca o olhar racional a-medida da realidade conhecida, ou seja, ele abarcaria toda a estruturação do mundo retomando-o nessa correlação com seu próprio olhar. Entretanto, a consciência intencional não mais faria a não ser pôr o objeto de modo a satisfazer uma intuição, por assumir-se enquanto dativo a partir do qual as demais coisas poderiam ser pensadas em sua "coisa mesma'. É válido ressaltar que a consciência intencional, com Husserl, não diz respeito a uma região abstrata no mundo, mas um ser real, ${ }^{14}$ imanente à sua verdade, porém, que dirige-se essencialmente à sua realidade exterior. Nessa medida, o movimento da intencionalidade, diz Husserl, consiste nessa constante retomada do mundo natural sob os olhos da vista pura da cogitatio real, emanada enquanto resquício da abstração eidética. Assim, se por um lado há essa vida sempre presente junto de si mesma temporalizando-se de modo imanente, por outro lado, esse infindo desejo que nos faz eclodir e ir em busca de satisfação, seja lá qual for a intenção jamais nos abandona.

\footnotetext{
${ }^{2}$ De acordo como Lalande (1999, p. 397), a definição geral de fenomenologia seria: “estudo descritivo de um conjunto de fenômenos, tal como eles se manifestam no tempo ou no espaço, por oposição quer às leis abstratas e fixas destes fenômenos, quer à realidade transcendente de que seriam a manifestação, quer à crítica normativa da sua legitimidade". Em um sentido mais particular diz-se "do método e do sistema de E. Husserl, assim como das doutrinas que são consideradas como ligadas a eles". Abbagnano (2000, p. 437) tem uma definição parecida de fenomenologia: "descrição daquilo que aparece ou ciência que tem como objetivo ou projeto essa descrição".
}

SOUTO, Symon Sales. A reversibilidade ontológica no conceito de imanência. Griot : Revista de Filosofia, Amargosa - BA, v.20, n.2, p.61-74, junho, 2020. 
O grande problema observado pelo autor supracitado consiste na primazia da doação do Ser ao ego que o vê, fazendo com que essa subordinação do aparecer puro enquanto tal à estrutura da correlação não só distancie o fenômeno da sua fenomenalidade que lhe é própria, bem como, deslegitimaria a própria relação em si, isto é, o Fundo comum onde e pelo qual essa correlação poder-se-á cumprir-se em sua plenitude. No tocante à questão, Michel Henry observa que só há a possibilidade de falarmos de um Fundo comum onde as correlações poder-se-ão ser pensadas se o desvelar fenomênico da Fenomenalidade que lhe é própria estiver sido trazido para o interior mesmo da própria revelação de afastando-se, por sua vez, da transcendência de um puro ver que a dá enquanto fenômeno.

Entendemos que a aspiração da consciência enquanto intenção, significa agir de modo a pôr o objeto que ela visa e, consequentemente, que ela pode realizar trazendo-o à clara et distinta perceptio, entretanto, diz Levinás que essa relação pressupõe outro tipo de relação que não é a relação à objetos. Segundo o Filósofo:

\begin{abstract}
A menos que todo o interesse da investigação anunciada, em vez de incidir na correlação sujeito-objeto, que definiria a intencionalidade, decorra de outro dinamismo que anima a intencionalidade. $O$ seu verdadeiro enigma não consistiria na presença juntos dos objetos, mas no novo sentido que ela permite dar a essa presença [...]. A intencionalidade designa, assim, uma relação com o objeto, mas uma relação tal que contém em si, essencialmente, um sentido, implícito. A presença junto das coisas implica em uma outra presença junto delas, que se ignora, outros horizontes correlativos dessas intenções implícitas, e que a mais atenta e escrupulosa consideração do objeto dado na atitude ingênua não conseguiria descobrir [...]. Estamos para lá do idealismo e do realismo, uma vez que o ser não se encontra nem no pensamento, nem fora do pensamento, mas que o próprio pensamento está fora de si mesmo. É preciso um segundo ato e um espírito serôdio para descobrir os horizontes escondidos que já não são o contexto desse objeto, mas os dadores transcendentais do seu sentido. Para deter o mundo e a verdade. É preciso mais do que o instante ou a eternidade da evidência" (LEVINÁS, 1959, pp.156-164).
\end{abstract}

Entendemos com Levinás que, sendo a correlação um movimento que nos leva sempre a algo, o encontro dessa correlação entre consciência intencional e objetos pressupõe sempre e, a todo modo, algo que não é nem a consciência e, tampouco, o objeto, mas que funda a possibilidade dessa própria relação. Trata-se de uma relação mais íntima, isto é, todavia, mais primordial e que estaria na base de todos os atos intencionais. Em outras palavras, trata-se de um movimento que não nos leva à objetos, mas a uma esfera outra que está para essa relação da consciência e seus objetos. É nesse e sob esse Fundo que se realiza a própria possibilidade de relação, logo, apresentar-se-ia enquanto dimensão anterior, todavia, mais primordial que a relação intencional e, por esta razão, a fenomenologia dever-se-ia “ultrapassar a intenção na própria intenção" (LEVINÁS, 1959, p.159).

A crítica Levinasiana parece-nos evidente. A aspiração da intenção é um movimento de visada, isto é, uma saída Fora de si que necessita encontrar nessa saída algo que esteja realmente fora de si, caso contrário, todo o projeto fenomenológico husserliano se encarceraria entre as amarras solipsistas. Deste modo, há e deve haver algo posto diante da consciência, no entanto, que apenas tornar-se-ia presente se a própria consciência intencional, no processo de presentificação, p.61-74, junho, 2020 . 
trouxesse-lo à Sua presença. ${ }^{3}$ Mas, o que significa tomar consciência de - besinner? Ao que podemos entender, no simples existir da consciência, o sentido é aquilo que está sendo pressuposto - meinung -, ou seja, o que está sendo visado, conduzindo-o de seu conhecimento vago a seu preenchimento sob bases seguras que conferir-lhe-ão claridade.

Lembremos que a consciência intencional, com Husserl, deve ser tomada enquanto Gegebenheit, afinal, na origem de todo e qualquer ato intencional, tudo o que é dito ou visto enquanto tal, já pressupõe esse fluxo imanente das vivências, isto é, a própria vida dessa consciência enquanto dado absoluto. Deste modo, sendo a intencionalidade da consciência uma experiência originária que, no seu curso, o aparecer do fenômeno corresponderia, conforme dissemos, a esse encontro original do sujeito com o mundo representado, ela não nos daria uma imagem congelada, mas, a presentificação de algo a partir de uma intenção de significação, de modo que, esse encontro entre o aparecer da coisa e sua significação pela consciência significaria, justamente, esse encontro entre a vivência e o objeto da consciência que só é possível, por um lado, reconhecendo o limite dessa apreciação da intenção que, no caso de Levinás, é o rosto de outrem. Assim, para Levinás:

\begin{abstract}
A flutuação entre a liberdade do idealismo transcendental e o mundo [...] sem que nenhum desses termos seja sacrificado - talvez seja a própria Sinngebung, o ato de emprestar um sentido que atravessa e sustenta todo o ser [...] O elo entre a situação e o objeto que a ela se refere, bem como o elo entre os fenômenos que constituem a unidade de uma situação são tão necessários quanto os elos de dedução (1959, p. 162).
\end{abstract}

O interesse de pensamento levinasiano, sabemos, gira em torno de outrem. Segundo ele, a co-extensividade do pensamento e da relação sujeito-objeto deixa oculto uma relação com o outro que não pode ser nem uma limitação intolerável de quem pensa e, tampouco, uma mera apreensão de outrem pelo mesmo como um conteúdo qualquer. Sua preocupação, portanto, gira em torno de desvincular a neutralização do outro pelo mesmo dada a atividade da representação. Em outras palavras, o intuito de Levinás consiste em desvencilhar a Sinngebung da atividade da representação para uma outra Sinngebung ética onde o rosto de outrem seja respeitado e visado com independência dos atos objetivantes (LEVINÁS, 1959, p164).

Michel Henry, por sua vez, preocupa-se em considerar o lugar ontológico em que esse contra polo chamado outrem ocupa. Para ele, apenas reconhecendo a imanência absoluta de sua doação, é que a correlação intencional reconheceria, obrigatoriamente, um certo limite de apropriação que, segundo ele, não só ultrapassaria a intenção na própria intenção, mas deslegitimaria a pretensão absoluta da consciência intencional enquanto Gegebenheitem detrimento de outrem. Dito de outro modo, a Sinngebung passaria a ser reconhecida através dessa presença imediata junto as coisas, mediante o desvelar do acontecimento ontológico fundamental enquanto base concreta da experiência humana. Somente esse acontecimento ontológico fundamental seria, aos seus olhos, o acontecimento primordial capaz de chocar meu rosto próprio com o rosto de outrem.

\footnotetext{
${ }^{3}$ Eis, pois, a base da divergência filosófica entre a Fenomenologia intencional de Husserl e a Fenomenologia Material de Michel Henry. Enquanto o primeiro da primazia a correlação, o segundo se questiona pelo aparecer na Hyléna materialidade de sua impressionalidade pura, isto é, sob sua doação antes do próprio visar intencional, entendendo-a como conditio sine qua non para que a doação noemática a título de correlato intencional possa se cumprir em sua plenitude.
} p.61-74, junho, 2020. 
Na mesma linha de pensamento de Levinás, Michel Henry comenta que Husserl se deteve no que é visto nesse ver primordial, no entanto, nada apareceria se o aparecer puro não aparecesse por si mesmo, isto é, se não houvesse um acontecimento primordial onde o ver e o visto por ele pudessem dar-se um ao outro. Porém, para Levinás, o choque com rosto de outrem apresentar-se-ia como acontecimento primordial e Michel Henry se questiona, por sua vez, sob o modo em que se dá a violência originária da vida em seu nascimento transcendental apodítico sofrida por cada ego, haja vista que, para que possa haver esse acontecimento primordial é preciso que ego e alter ego, de algum modo, sejam. Deste modo, aos olhos de Michel Henry, nem Husserl e, tampouco, Levinás compreenderam o desvelar imanente do Ser absoluto em seu acontecimento ontológico fundamental, ainda que o segundo tenha compreendido a importância de não absorção do outro pelo mesmo nesse eterno anelo em trazer tudo o que de certo modo se dá para a vista pura que o vê, tal como ele é em si mesmo.

Assim, apesar da genialidade Husserl, Michel Henry afirma que o golpe de mão da fenomenologia "radica em interpretar sempre e em todo momento o poder de revelação do impressional e afetivo como tal, 'desta função em contraste com o caráter informante', ou seja, de seu excludente de toda a intencionalidade, como constituinte precisamente por esta" (2009, p.53). Nosso autor compreende que o Ser deve poder mostrar-se, no entanto, insistimos que se o aparecer puro não aparecesse enquanto tal, nada daquilo que aparece poderia ter sido aparecido. Mas em que consiste esse puro ato de aparecer em e por si mesmo? Para responder à questão, nos é preciso entender que sua discussão é ontológica e não metafísica diferenciando-se, por sua vez, da fenomenologia Levinasiana.

Mas, para que seja possível des-velar o acontecimento originário do Ser absoluto na imanência absoluta de sua autorrevelação nesse Fundo comum que, bem-dito por Levinás, está na base de todos os atos e, nessa medida, apresentar-se-ia enquanto Fundo Ontológico existencial, Henry pensa ser necessário subordinar toda a Ontologia à Fenomenologia, haja vista que, segundo ele, apenas o conhecimento dessa estrutura primordial ulterior à relação, é que nos faz reconhecer, $a$ priori, uma certa limitação desse desejo desenfreante da intencionalidade que acaba por subordinar o discurso ao presente fixando-o à visibilidade.

Para nós, tanto Levinás quanto Michel Henry caminharam rumo a uma redução mais radical, ou seja, àquilo que seria, todavia, mais originário que essa relação intencional com o mundo. $\mathrm{O}$ ganho dessas novas fenomenologias, é claro, consiste em romper-se com esse horizonte finito de visibilidade e, com isso, trazer-nos a possibilidade de uma fenomenologia do invisível. No entanto, tais pretensões não seriam um non sense? Estaríamos, todavia, dentro dos limites da própria fenomenologia? Com essas questões em mente gostaríamos de dilucidar, a partir da ontoFenomenologia Material de Michel Henry, seu método fenomenológico radical da Revelação do Ser invisível enquanto autogeração da Vida imanente. Destarte, se em Levinás deve haver uma ultrapassagem da intenção na própria intenção a fim de recuperar o originário mais antigo que o visível e que viria a conferir sentido ao próprio campo de visibilidade, Michel Henry insiste, todavia, na ressignificação de enfoque sobre a questão do sujeito com vistas a sua perca de soberania frente a fenomenalidade do Ser, no entanto, é sob a fenomenalidade do segundo que nos importará analisar a fim de compreendermos em que medida o filósofo de Montpellier ressignifica a questão da Imanência absoluta e, ressignificando-a, apresenta-nos um outro sentido de Absoluto. p.61-74, junho, 2020. 


\section{Onto-fenomenologia radical de Michel Henry: sobre a doação ontológica imanente do ser absoluto}

É preciso entender, conforme nos indica Garcia-Baró, que Michel Henry se distancia de "sinalar condições de possibilidades lógicas ou subjetivas e caminha em direção ao ser mesmo como última condição" (1963, p.05). No entanto, como é possível falarmos desta experiência de si do ser? Se é absoluto, então, o movimento do puro ato de aparecer desvela-se imanente, mas de que modo é possível descrevermos essa experiência?

O devir fenomênico do ser que de que nos fala Henry não é mera descrição, mas pura afecção de si num corpo próprio e, nesta medida, apresentar-se-ia como um bom fundamento por converter da transcendência para uma imanência pura a fenomenalidade própria do ser. Comentando a respeito, Furtado nos indica que a essência dos fenômenos na Fenomenologia Material "não se opõe à fenomenalidade que ela torna possível, não está além ou aquém da manifestação que é sua obra. Ela se manifesta em outro lugar, de uma outra forma, de forma imanente, através da afetividade da vida" (2008, p. 237). Sobre a afetividade desta essência, sentimo-la em nossa carne ${ }^{4}$ e seu processo de fenomenalização:

\footnotetext{
Não é uma auto posição, uma auto objetivação, ela não se põe diante de si para afetar-se de si mesma, no sentido de uma manifestação de si que seria a manifestação do objeto. Com efeito, é isso que a vida não pode ser. A vida se afeta, é para si, sem se propor a si mesma na objetivação da ek-stasis, ela se sente sem que isso seja pela intermediação do sentido, de um sentido interno nem de um sentido qualquer em geral (HENRY, 2011, p.207).
}

Nessa medida, se o devir fenomênico do ser na Fenomenologia Material desvela-se em uma interioridade abissal, Rosa comenta que é, então:

Na autorrevelação da vida absoluta, como doação passiva para si mesma, que também cada Soi-même é dado e vem a ser, não apenas como eu transcendental, mas como vivente, singular, concreto, nas suas moções mais secretas e humildes e em todos os seus poderes. Não é, portanto, a vida irreal, noemática, essência abstrata, mas a vida concreta dos viventes (o Pedro, a Ivete) [...]. As modalidades subjetivas mais imediatas para nós desta passividade são o sentir-se a sentir, o ver-se a ver (viderevideor) o padecer-se (de pathos), ser para si mesmo uma doação originária (2006, p.12).

Aceito esse pressuposto, toda e qualquer experiência no tocante às subjetividades dever-se-ia ser repensada, afinal, "o ser não precisa negar-se em sua universalidade para se dar o momento de sua particularidade. Muito pelo contrário, o particular, se quisermos utilizar esta linguagem, é a essência do ser, sua possibilidade mais íntima, e o desdobramento de sua positividade" (HENRY, 2011, p. 208). Para Michel Henry o par vida e vivente, isto é, invisível e visível tornam-se polos indissociáveis para compreendermos o devir efetivo da fenomenalidade "no já de sua condição primitiva que é, como tal, como este 'já' da manifestação pura efetiva que faz possível todo o comportamento e todo passo anterior, o absoluto. O ser se manifesta 'já' de entrada, com

${ }^{4}$ Carne, lida também enquanto ipseidade de um si vivente se "constitui desde dentro como esta experiência que é o que ela é não na identidade exterior da coisa da que afirmamos que é a mesma, mas que é o que ela é em qualidade desta experiência ajustada ponto a ponto a si, sentindo-se e experimentando-se desta forma. Em outros termos: a essência da subjetividade absoluta em quanto puro fato de experimentar-se a si mesma imediatamente é de maneira idêntica a essência da ipseidade" (HENRY, 2009, p.213).

SOUTO, Symon Sales. A reversibilidade ontológica no conceito de imanência. Griot : Revista de Filosofia, Amargosa - BA, v.20, n.2, p.61-74, junho, 2020. 
anterioridade, a todo trabalho de elucidação" (HENRY, 1963, pp. 141-142). No entanto, como é possível descrever esse aparecer do invisível no horizonte de visibilidade com anterioridade a todo trabalho de elucidação?

Sabe-se que o fenômeno nos atinge; nos afeta, no entanto, nada daquilo que já não tenha sido anteriormente doado pode nos afetar. Ou seja, segundo Henry, a indubitabilidade da doação não é dada pelo ego transcendental. Ao contrário, ele tem apenas o poder de delimitá-la, mas jamais de doá-la e, por esta razão, Levinás afirmara que a representação do mundo tomado enquanto fenômeno é garantido por aquilo que não pode ser representado, no entanto, ainda que o rosto de outrem seja o irrepresentável, isto é, o limite entre o que pode ser visto e o invisível que se desvela a despeito de tudo o que se vê, isso não implicaria, segundo Michel Henry, no como da fenomenalização desse invisível enquanto tal. Doravante, com o filósofo de Montpellier, duas dimensões irão dilacerar o ser em sua unidade ad intra. Mundo sensível e mundo inteligível, visível e invisível caracterizar-se-iam duas dimensões de uma mesma realidade, no entanto, não há ruptura entre elas, mas uma linearidade no decorrer da sua própria doação.

O que o fenomenólogo da Vida pretende consiste em dizer, com todo rigor, que a Vida, isto é, essa simplicidade vital cria o Todo antes mesmo das partes de modo imediato e simples, a saber, em e por si mesmo, logo, o deslocamento da cogitatio, a sua vinda baixo o olhar, não faz dela um dado absoluto, uma vez que, tratar-se-ia de um fenômeno reduzido na e por uma consciência intencional em detrimento da essência original da fenomenalidade mesma enquanto tal, isto é, a essência da Vida que, conforme Levinás, se desvela sob o limite do rosto. Ou sob a pele, diria Michel Henry.

De antemão, sabemos que a verdadeira vida está ausente, mas nós estamos verdadeiramente no mundo, logo, como falar dessa revelação Absoluta do invisível da vida no processo da realidade mesma enquanto tal? Como se dá essa relação da Imanência na Transcendência, isto é, dessa Vida no mundo mediante um ato que decorre no seio mesmo de sua própria fenomenalidade absoluta? Como, pois o Ser desvela-se fenômeno no seio de soi-même? Estaríamos, todavia, sob o domínio da Fenomenologia? Seguimos, pois, rumo a uma análise fenomenológica rigorosa do existente humano a partir desta nova forma de conceber a fenomenologia buscando, por sua vez, compreender a proposta Henryriana de uma Fenomenologia do Nascimento como resposta a essa dualidade visívelinvisível.

\section{Fenomenologia do nascimento: a retomada do absoluto}

Observamos com Levinás um elemento que resiste, radicalmente, a totalização. A unicidade de cada presente acaba, segundo o autor, esmagada por um porvir totalizante racional. É justamente sobre esse porvir totalizante racional que, tanto Emmanuel Levinás quanto Michel Henry pretendem se esquivar, haja vista que, tais atos são a face da guerra e essa, por sua vez, é Barbárie. ${ }^{5}$

O Ser possui a ossatura de um sujeito individual, isto é, um núcleo humano que é lido enquanto um eu concreto. Em outras palavras, a fenomenalidade do ser se concretiza chez-moi de modo que, se assim não o fosse, não seria possível a mônada husserliana romper-se com a totalidade. Assim, a grosso modo, a relação entre egos, ou melhor, a relação entre rostos seria para Levinás o acontecimento que permite o entrave da totalização, ligada ao processo no qual o registro

${ }^{5}$ HENRY, M. A barbárie. Trad. Luiz Paulo Rouanet. São Paulo: É Realizações Editora, 2012 b.

SOUTO, Symon Sales. A reversibilidade ontológica no conceito de imanência. Griot : Revista de Filosofia, Amargosa - BA, v.20, n.2, p.61-74, junho, 2020. 
do fenômeno é realçado trazendo-o ao Logos. Ou seja, o rosto levinasiano é o único objeto dentre os demais que não pode ser trazido para o registro da imanência, logo, é o rosto de outrem que rompe com o a totalização de tudo pelo eu, haja vista que, antes de ser donné a uma consciência intencional que o visa, o rosto de outrem é donnant. Nessa medida, sua significação precede à correlação intencional e, por essa razão, apresentar-se-ia como conceito limite da fenomenalidade, isto é, enquanto um excesso em relação à manifestação tal como é compreendida aos moldes de Husserl.

Destarte, rosto em Levinás é um aparecer que perpassa a forma de todo o aparecer concebível e, nessa medida, é invisível. Assim, a lógica do aparecer dá lugar a uma lógica do expressar, ou seja, um tipo de relação ligado pelo discurso, pela linguagem e não em sua doação como fenômeno, cuja palavra vem de outrem. No entanto, libertar o vocabulário fenomenológico da ontologia deixa, todavia, escapar aquilo que, aos olhos de Michel Henry, consiste no Verdadeiro Acontecimento Originário, a saber, a fenomenalidade do ser em seu constante processo de fenomenalização, o aparecer que aparece como aparecendo de modo irredutível a si, em sua permanência inquebrantável de si a si mesmo que, segundo ele, não é mera contingência, mas obra sua mesma. Em suas palavras, o verdadeiro acontecimento originário:

É tão só aquilo que experiencia em si mesmo sem diferir-se de si, de modo que esta experiência é uma prova de si e não de outra coisa, uma autorrevelação em sentido radical [...]. É nesta Afetividade e como Afetividade que se cumpre a autorrevelação da vida. A afetividade originária é a matéria fenomenológica da autorrevelação que constitui a essência da vida. Ela faz desta matéria uma matéria impressional que jamais é uma matéria inerte, a identidade morta de uma coisa. É uma matéria impressional experienciando-se a si mesma impressionalmente e não deixando de o fazer, uma auto-impressionalidade viva (HENRY, 2000 , p. 74). ${ }^{6}$

É preciso entender que não há a possibilidade, a não ser metodológica, de "separar a essência compreendida em sua pureza e o devir fenomênico que ela realiza" (HENRY, 1963, p.139). Ou seja, Imanência, conforme insiste Henry, implica que "o devir fenomênico deve se realizar na essência e por ela" (1963, p.138) e não sob o ser visto por uma vista pura de uma cogitatio real. Seu aparecer encontra sua realização no seio mesmo da essência, sem vislumbre de transcendente algum e, por compreender si mesma na afecção de si, ela é autônoma. Mas, como se dá essa radicalidade no conceito de imanência?

O dever poder manifestar-se da essência, conforme nos mostra Henry (1963, p.141), possui um caráter ambíguo. Por um lado, quando a possibilidade que tem o ser de mostrar-se é dependente do trabalho metodológico da fenomenologia, o desvelado por ela não diz respeito ao ato de aparecer da fenomenalidade pura enquanto tal, ${ }^{7}$ isto é, não a faz vir à luz efetivamente tal como é, em e por si mesma. Por outro lado, nos mostra a Fenomenologia Material que "a manifestação do ser não

\footnotetext{
${ }^{6}$ Deste modo, o ser ainda que seja sempre o ser de um ente, o si vivente, uma ipseidade, diz respeito ao "Absoluto em repetição principal da vida auto-afetando-se para sempre na sua intensidade sempre nova ou diferenciada, é o sentimento da vida enquanto nosso 'ser sentido' por excelência: saber plenamente que estamos mergulhados de maneira única na vida, o que significa viver enquanto indivíduo sem fuga ou subterfúgio possíveis" (KÜHN, 2010, p.56, grifos do autor).

7"A determinação do ente pelo ser expressa a dependência do que aparece com respeito ao ato de aparecer considerado em e por si" (HENRY, 1963, p.142).
} p.61-74, junho, 2020. 
resulta de qualquer progresso, não depende de qualquer processo, ela não está relacionada com o devir de qualquer saber [...] porque ela é a realidade originária, ela não se fenomenaliza jamais no campo da irrealidade constitutiva de toda transcendência" (DUFOUR-KOWALSKA 1980, p. 39). Nas palavras de Michel Henry, "a relação está presente porque o ser se manifesta". Somente sob o fundo dessa manifestação, acrescenta nosso autor, "o ente é o que é" (1963, p.142).

A tradição fenomenológica, diz Michel Henry, tratou dessa possibilidade do mostrar-se fenomênico da fenomenalidade pura, a partir de um poder elucidativo de uma consciência intencional, seja atendo-se ao visto pelo ver ou em uma transgressão da própria intencionalidade. No entanto, a Verdade Originária não está aquém ou além da consciência, jamais exterior. Ela é a manifestação do Absoluto em sua absolutez, isto é, a manifestação imediata da Presença, "é a Presença na Sua Presença, o Ser presente enquanto tal, no sentido de que está presente a si mesmo. Sua manifestação é imediata e, jamais, mediata" (HENRY, 1963, p. 143).

Somos auto engendramento na e pela Vida e, nesse sentido, imanência absoluta. Assim, sentimo-nos a nós mesmos de modo imediato, irrepresentacional, pois, sentir-se de imediato na Presença deste absoluto que é a Vida, nos faz confundir-nos com ela. O saber imanente do ego transcendental é, portanto, o modo pelo qual essa consciência, essa carne, esse corpo vivo se compreende a si mesma não a partir do mundo, mas a partir de uma compreensão ontofenomenológica radicalmente independente de toda compreensão existencial, tendo em vista que "a essência da manifestação encontra nela mesma sua realidade enquanto que a realidade efetiva da manifestação que se produz nela, encontra também nela, seu próprio fundamento" (HENRY, 1963, pp.139-140).

Deste modo, o ganho da Fenomenologia Material consiste em denunciar que para a efetividade de sua manifestação, ele deve pressupor sempre, como sua condição, "o devir efetivo da manifestação na obra pura da essência, a selbständigkeit desta" (HENRY, 1963, p.138). Eis, pois, o que possibilita separarmos eideticamente a essência compreendida em sua pureza e o devir que ela realiza. Assim, a auto evidência da cogitatio é, na Fenomenologia Material, a manifestação do absoluto em sua absolutez que, por essência, tem o hábito de sentir-se a si mesma. Só há relação entre consciência e objeto porque o ser mesmo já está presente, contudo, essa presença só é possível graças à manifestação de si do ser em sua estrutura ontológica universal. A consciência intencional, por sua vez, só é capaz de falar daquilo que aparece como aparecendo, inclusive a si mesma, no entanto, o ato originário pelo qual esse movimento tem lugar precede a todo ato de captação, pois, conforme apontamos, encontra sua realização na selbständigkeit da essência.

A compreensão existencial ${ }^{8}$ de si se caracteriza como um modo particular da vida na consciência, uma compreensão da existência por ela mesma. É sempre um conteúdo visado, noésis e noema, uma compreensão explícita do objeto. Já a compreensão ontológica do ser, diz Henry, independe de como ela se representa, pois, conforme dissemos, a separação da compreensão existencial da compreensão ontológica é irreal, uma vez que, é somente essa unidade ad intra da essência com a existência que constitui a 'coisa mesma' do ser absoluto. ${ }^{9}$ Nas palavras de Michel Henry:

\footnotetext{
${ }^{8}$ Para o conceito de representação; estrutura ontológica e compreensão existencial (Cf. HENRY, 1963, §18, pp. 147-155).

${ }^{9}$ A separação da essência e a existência na representação é uma separação irreal. Sem embargo, esta separação não é irreal porque se falseia, mas porque se produz dentro da representação, ou seja, como uma significação a que aponta a consciência em um modo determinado de sua vida" (HENRY, 1963, p.157).
}

SOUTO, Symon Sales. A reversibilidade ontológica no conceito de imanência. Griot : Revista de Filosofia, Amargosa - BA, v.20, n.2, p.61-74, junho, 2020. 


\begin{abstract}
Que o ser deva poder manifestar-se não significa que a manifestação de si do ser possa ou deva aderir-se à essência do ser no transcurso ou ao término de um processo que permita a esta essência realizar-se; significa que a essência do ser é a manifestação de si. A manifestação de si é a essência da manifestação [...]. É originária, o que quer dizer que não é obra do saber filosófico, mas da essência mesma. A manifestação de si da essência não é obra do saber filosófico. Este a pressupõe constantemente como a condição mesma de seu cumprimento $\left(1963\right.$, p.146, grifos do autor). ${ }^{10}$
\end{abstract}

Em suma, radicalizando a doação da própria cogitatio, Michel Henry defende sua tese de que a doação do absoluto em sua absolutez de si é anterior à tomada de consciência do ato de aparecer em virtude do qual ele aparece. O saber de si, diz nosso autor, se opõe ao ser para si que nos é revelado dentro de um ato determinado de captação e compreensão (Cf. HENRY, 1963, §19). Saber de si, ou seja, sentir-se a si mesmo enquanto absoluta presença de si é "autodoação na qual todo o poder se recebe a si mesmo e é por isso investido de si" (HENRY, 2000, p. 205). Nesta medida, compreende-se que a Fenomenologia Material dita uma Fenomenologia da Vida, pois "viver, significa ser" (HENRY, 2011, p. 199). Somos no instante em que a vida nos afeta e nos faz viventes em sua auto afecção de si e, por isso, "a filosofia chega sempre, demasiado, tarde, no que diz respeito à fenomenalidade do fenômeno, pois, o que ela disse era no princípio" (HENRY, 1963, p.170, grifos nosso). Chegar tarde, significa, conforme apontou Levinás, na impossibilidade de totalização da intencionalidade graças a irrepresentabilidade do Invisível que se desvela de outro modo que ser.

Por fim, somos capazes de concluir que todo o vivente "existe por si mesmo sem nenhum contexto, sem o suporte de nenhum ser exterior” (HENRY, 1963, p.57). Ele é auto afecção de si na e pela vida e, por esta razão, o choque com o rosto de outrem marca um acontecimento Fundamental, a saber, o instante em que duas imanências absolutas se descobrem juntas num Fundo comum, uníssono tanto para moi quanto para soi. Essa doação invisível do infinito no horizonte finito de visibilidade é, pois, a maravilha da Fenomenologia Material.

\title{
Considerações finais
}

Michel Henry propõe, conforme vimos, um método capaz de revelar outro acontecimento, todavia, mais originário do Ser, a saber, sua autorrevelação que se cumpre como pathos na Carne impressional de uma ipseidade. Nós entendemos que é justamente essa análise da Vida, isto é, a compreensão da autogeração patética da Vida como matéria fenomenológica pura em sua autoimpressionalidade que reformulará não só a ideia do desvelar absoluto do Ser, bem como, a reabertura da significação ontológica do conceito de Soi-même. No entanto, sua filosofia só é possível mediante a substituição do aparecer ek-stático do mundo pelo aparecer da Vida, na e pela qual, toda a Carne é passível de ser.

A Fenomenologia da Vida assim pensada, trata-se de um modo originário segundo o qual a fenomenalidade fenomeniza-se sob a forma de uma ipseidade absolutamente originária, ou seja, é o modo pelo qual essa vida absoluta vem a si mesma no sentir-se imediato de si, mediante a descrição

10“De onde decorrem uma dupla conclusão: 'a fenomenalidade é o ser verdadeiro do ente' [bem como] uma definição de fenomenologia: 'a fenomenologia é a tentativa de auto fundação do saber humano pelo retorno a auto fundação do ente" (HENRY, 2006, p.07, grifo nosso).

70

SOUTO, Symon Sales. A reversibilidade ontológica no conceito de imanência. Griot : Revista de Filosofia, Amargosa - BA, v.20, n.2, p.61-74, junho, 2020. 
do processo de revelação da Vida em sua Arquirrevelação no Verbo. ${ }^{11}$ Destarte, o rosto de outrem, ainda que seja o limite através do qual a correlação da intenção não só se rompe com a Totalidade, mas reconhece o Infinito por detrás desse movimento enquanto possibilidade ulterior de seu próprio acontecimento, desvela-nos a impotência de todo o poder com respeito ao poder absoluto que o pôs nele mesmo e contra o qual ele nada pode, ou seja, a impossibilidade em que o ego transcendental encontra de se desfazer de si mediante esse laço entre visível e invisível.

Dada em sua imediação patética, a Carne não se preocupando em ver e nem em ser vista enquanto tal, pois, ligada ao Poder a Afetividade se encontra ligada ao princípio da ação de modo que essa já não pode ser compreendida senão na sua manifestação real; afetiva, é o que nos permite compreender a dialética patética entre visível e invisível do absoluto a partir da duplicidade do aparecer. Com ela, somos capazes de interpretar a situação respectiva dos termos inconciliáveis posto em relação no espírito, não como uma passagem do primeiro ao segundo ou um limite na apropriação de si, mas como um crescimento simultâneo e vertiginoso de dois elementos presentes (Cf. HENRY, 2006, p.261).

Por fim, dada as considerações arroladas nesse artigo, inferimos que nosso corpo possui em si essa capacidade real de poder que é, aos olhos de Henry, o que constitui a Sensualidade Primordial, ou seja, essa possibilidade de sentir tudo o que quer que seja. A carne Henryriana é essa capacidade de experimentar sensações ou de realizar movimentos que é regida graças a essa possibilidade primordial de poder, sempre afetiva, constitutiva do Si transcendental na Ipseidade da qual nossa carne é posta em si mesma, em cada um dos seus poderes que lhes são doados na Imanência absoluta de sua autorrevelação e que, doravante são teus (HENRY, 2006, p. 296).

Eis, pois, o limite da apropriação intencional, a saber, essa impossibilidade abissal de doar esse poder que é constitutivo do Si transcendental. Estando o desejo insatisfeito com tudo aquilo que deseja, afinal, ele quer e pode querer sempre satisfazer seu próprio querer Henry se debruçará, retomando a Schopenhauer, sobre esse querer irreprimível que de desembaraçará no conceito de angústia. Sua filosofia trata, por conseguinte, dessa dinâmica do pathos, isto é, da angústia e do desejo que compreendem a Sensualidade Primordial de nossa Carne patética, no entanto, o estudo detalhado destas questões excede os limites propostos nesse artigo. Nosso intuito fora apresentarlhes que o ganho da Fenomenologia Material consiste, por sua vez, em dizer-nos que independente de todo e qualquer olhar, nossa Carne leva em si a suscetibilidade de se cumprir e, somente por esta razão, apresentar-se-ia enquanto limite na apropriação do movimento intencional e, com isso, a ideia de Infinito poder-nos-á ser (re)pensada sem que para isso devamos pressupor “de fato, [...] a existência em si anterior do ego puro e das suas cogitationes" (HUSSERL, 2001, p.12).

${ }^{11}$ Para um estudo detalhado da questão, conferir a trilogia Henryriana dedicada à questão da Encarnação (1996), Verdade (2000) e da Palavra (2002).

71

SOUTO, Symon Sales. A reversibilidade ontológica no conceito de imanência. Griot : Revista de Filosofia, Amargosa - BA, v.20, n.2, p.61-74, junho, 2020. 


\section{Referências}

ALVES M.S.P., SANTOS J. M., SÁ A.F. de (Orgs.). Humano e Inumano. A dignidade do Homeme os Novos Desafios. Actas do II Congresso Internacional da Associação Portuguesa de Filosofia Fenomenológica, 10 e 11 de março de 2005 (Universidade de Coimbra), Revista Phainomenon. Estudos de Fenomenologia, Lisboa, Centro de Filosofia da Universidade de Lisboa, 2006, pp. 279290.

ÂNGULO, J. Fenomenología de la vida. Universitas philosophica, 37, 2001, pp.113-126. Bogotá. Disponívelem: file:///C:/Users/Symon\%20Sales/Downloads/11369Texto\%20del\%20art\%C3\%ADculo-41829-1-10-20141212\%20(1).pdf. Acesso em 10/08/2018.

BARBOSA, R.A ideia husserliana de fenomenologia. INCONФIDENTIA: Revista Eletrônica de Filosofia Mariana-MG, Volume 2, Número 2, janeiro-julho de 2014.

BARIENTOS RODRÍGUEZ, J. Cinco datos fenomenológicos premilinares para uma ontología de lasubjetividad a partir de Michel Henry leitor de Maine de Biran. Research Bulletin (Nihon University), 60, 2008, 29-54. Disponívelemhttps://datospdf.com/download/cinco_datosfenomenologicos_preliminares_para_unaontologia_de-la_subjetividad_

_5a4bda69b.7d7bcb74fd03aea_pdf_._Acesso em 01/09/2018.

CARDoso, Adelino; MIRANDA JUSTO, José M. (Orgs.) Sujeito e Passividade. Anais do Congresso. Lisboa: Colibri; CEFI, 2003.

CIOCAN, Cristian; KÜHN, Rolf; HATEM, Jad (Eds.). Henry's Radical Phenomenology. Romanian Society for Phenomenology e Humanitas, Studia Phaenomenologica, v. IX/2009.

COMTE-SPONVILlE, A. Dicionário filosófico. Trad. Eduardo Brandão. 1. ed. São Paulo: Martins Fontes,2003.

DEPRAZ, N. (1999). Husserl. Paris: Armand-Colin.

DEPRAZ, N. Compreender Husserl. Tradução de Fábio dos Santos. $3^{\circ}$ ed. Petrópolis, Rj: Vozes, 2011.

DUFOUR-KOWAISKA, G.Michel Henry, Une Philosophie de la vie et de la praxis, Paris, Vrin, 1980.

FRAGATA J. A fenomenologia de Husserl como fundamento da filosofia. $1^{\text {a }}$ ed: Braga, livraria cruz, 1956.

FURTADO, Luiz José. A filosofia de Michel Henry: uma crítica fenomenológica da fenomenologia. Dissertatio, p. 231-249, inverno/verão de 2008.

GALEFFI, D. O que é isto - a fenomenologia de Husserl? Ideação, Feira de Santana, n.5, p.13-36, jan. /jun. 2000. Disponível em: <http://pablo.deassis.net.br/wp-content/uploads/dante5fenomenologia.pdf $>$. Acesso em 7/7/2018.

GARCÍA-BARÓ, M. Introducción a la teoría de la verdad de Michel Henry, en M. HENRY, Fenomenología material, Ediciones Encuentro, S.A., Madrid, 2009.

GARCÍA-BARÓ, M. Alabanza de Michel Henry: Introducción a su edición de M. Henry, La Esencia de la Manifestación. Salamanca, Sígueme, 2016, 5-12.

GÉLY, R. La souffrance originaire de la vie et la souffrance au travail. Réflexions à partir de la phénoménologie radicale de Michel Henry. Colóquio Internacional de Lyon, 2008.

GIOVANNANGELI, D. La passion de l'origine; recherches sur l’eshétique transcendantale e la phénoménologie.Paris: Galilée, 2002.

72

SOUTO, Symon Sales. A reversibilidade ontológica no conceito de imanência. Griot : Revista de Filosofia, Amargosa - BA, v.20, n.2, p.61-74, junho, 2020. 
GRZIBOWSKI, Silvestre. Transcendência e ética: um estudo a partir de Emmanuel Levinás. São Leopoldo: Oikos, 2010.

GRZIBOWSKI, Silvestre. Intuição e percepção em Husserl: leituras de Emmanuel Levinás. Rev. Nufen: Phenom. Interd. | Belém, ago. - Dez., 2016. Disponível em: $<$ http://pepsic.bvsalud.org/pdf/rnufen/v8n2/a06.pdf>. Acesso em 27/07/2018.

HENRY, M. Fenomenologia não-intencional. Trad. José Rosa. LusoSofia: Press, 1992. Disponível em: www.lusosofia.net_Acesso em 10/09/2018.

HENRY, M. Encarnação: uma filosofia da carne. Trad. Florinda Martins. Portugal: Círculo de Leitores, 2000.

HENRY, M. Fenomenología de la vida. Trad. Miguel García-Baró, en M. GARCÍA-BARÓ - R. PINILLA (coords.) Pensar la vida. Documentos de trabajo, Madrid: Universidad Pontificia de Comillas, n. 48, pp. 17-31, 2003a.

HENRY, M.Phénoménologie de la naissance. Alter, revue de phénoménologie 2: Temporalité et affection, p. 295-312. 1994.

HENRY, M. Débat autor de l'oeuvre de Michel Henry. In Phénoménologie de la vie, T. IV, Paris: PUF, (2004). p. 224.

HENRY, M. O começo cartesiano e a ideia de fenomenologia. Trad. Adelino Cardoso. Covilhã: LusoSofia: Press, 2008. Disponível em: www.lusosofia.net. Acesso em 11/09/2018.

HENRY, M. Fenomenología Material. Trad. Javier Teira y Roberto Ranz. Madrid: Ediciones Encuentro, 2009b.

HENRY, M. L'essence de la manifestation. Paris: Épiméthée, PUF, 2011 b.

HENRY, M. A barbárie. Trad. Luiz Paulo Rouanet. São Paulo: É Realizações Editora, 2012 b.

HUSSERL, E. Problemas fundamentales de la fenomenología. Edición e traducción de C. Morenoy J. San-Martín. Madrid: Alianza Editorial, 1994.

HUSSERL, E. A ideia da fenomenologia. Lisboa: Edições 70,2000.

HUSSERL, E. Ideias para uma fenomenologia pura e para uma filosofia fenomenológica: introdução geral à fenomenologia. Tradução de Márcio Suzuki. Aparecida, SP; Ideias \&Letras, 2006.

ISIDRO PEREIRA, S. J. Dicionário grego-português e português-grego. 5. ed. Lisboa: Livraria Apostolado da Imprensa, 1976.

JEAN-LUC MARION, "Le corpssentant", Conferências de filosofia II, Campo das Letras, 2000, pp. $147-174$.

LAOUREUX, S. L’Immanence à la limite; recherches sur la phénoménologie de Michel Henry. Paris: CERF, 2005.

LAVIGNE, JEAN-FRANÇOIS. The paradox and limits of Michel Henry's concept of transcendence. International Journal of Philosophical Studies 17(3): 377-388, 2009.

LEVINÁS, E. Descobrindo a existência com Husserl e Heidegger (instituto Piaget).

LEVINÁS, E. Totalidade e Infinito. (Ed.70).

LEVINÁS, E. Humanismo do outro Homem. (Ed. Vozes).

LIPSITZ, M. Eros y nacimiento fuera de la ontología griega: Emmanuel Levinás y Michel Henry. Buenos Aires: Prometeo, 2004.

LIPSITZ, M. Vida y subjetividad: Los Descartes de Michel Henry.Tópicos. $<$ Http://www.scielo.org.ar/scielo.php?script=sci_arttext\&pid=S1666-485X2006000100002>. Acesso em 23/08/2018.

73

SOUTO, Symon Sales. A reversibilidade ontológica no conceito de imanência. Griot : Revista de Filosofia, Amargosa - BA, v.20, n.2, p.61-74, junho, 2020. 
MAGALHÃES, Fernando Silvestre Rosas. Caro cardo salutis: O Contributo de Michel Henry para uma Cristologia da Encarnação. 2008. Dissertação de Mestrado - Universidade Católica Portuguesa, Porto, 2008.

RIVERA, J. The contemplative self after Michel Henry, University of Notre Dame Press, Indiana, 2014.

SANTOS, Luciano Costa. O sujeito encarnado: a sensibilidade como paradigma ético em Emmanuel Lévinas. Ijuí: Unijuí, 2009.

SCHELER, M. Da essência da filosofia. Trad. Artur Morão. Luso Sofia: Press, 2002. Disponível em: www.lusosofia.net. Acesso em 10/08/2018.

SEBASTIEN, L. L'Immanence à la limite. Recherches sur la phénoménologie de Michel Henry(Passages). Un vol. de 269 pp. Paris, Cerf, 2005.

TOURINHO, C. O exercício da epoché e as variações do transcendente na fenomenologia de Edmund Husserl. Unisinos. Disponível em: <file://c:/users/ho/downloads/2588-7823-1-pb.pdf>. Acesso em $4 / 10 / 2018$.

TOURINHO, C. A radicalização da epoché fenomenológica: inversão do transcendente e oscilação do objeto intencional Husserl. Disponível em: <http://www.ufjf.br/eticaefilosofia/files/2009/08/16_2_tourinho.pdf> acesso em 14/09/2018.

TOURINHO, C. A estrutura do noema e a dupla concepção do objeto intencional em Husserl. Revista Veritas. Porto alegre-rs, v. 58, n. 03, p. 482-498, 2013.

Autor(a) para correspondência: Symon Sales Souto, Av. Roraima, nº 1000, Bairro Camobi, 97105-900, Santa Maria RS, Brasil.symonsalesouto@gmail.com 